\title{
Air quality monitoring and simulation on urban scale over Munich
}

Khorsandi, E., Baier, F., Erbertseder, T., Bittner, M.

E. Khorsandi, F. Baier, T. Erbertseder, M. Bittner, "Air quality monitoring and simulation on urban scale over Munich," Proc. SPIE 10793, Remote Sensing Technologies and Applications in Urban Environments III, 1079303 (26

October 2018); doi: 10.1117/12.2503969

SPIE. Event: SPIE Remote Sensing, 2018, Berlin, Germany 


\title{
Air quality monitoring and simulation on urban scale over Munich
}

\author{
E. Khorsandi*a ${ }^{*}$ F. Baier ${ }^{\mathrm{b}}$, T. Erbertseder ${ }^{\mathrm{b}}$, M. Bittner ${ }^{\mathrm{a}, \mathrm{b}}$

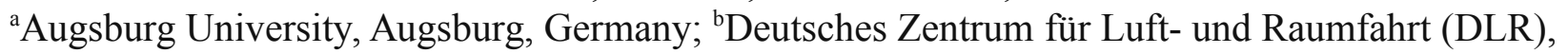 \\ Oberpfaffenhofen, Germany
}

\begin{abstract}
Chemical-transport models are a persuasive tool to predict and study air pollution on different temporal and spatial scales. However, due to the complexity of physics and chemistry of air pollutants' interactions and lack of precise input data, these models have uncertainties. In particular, most of the emission data have a too coarse resolution and are not appropriate for application in urban scale air quality modeling. In this study, a downscaling approach is utilized for emission data in order to improve the air pollutants concentration simulation over Munich city using the POLYPHEMUS/DLR chemistry-transport model (CTM). Traffic emission from the Bavarian Emission Kataster (EKATBY) 2004 anthropogenic emissions dataset with $2 \mathrm{~km}$ resolution is downscaled to $100 \mathrm{~m}$ with regard to the highresolution OpenStreetMap roads paths and areal emission sources are relocated on the most populated and active sites which have been determined from VIIRS NOAA satellite-derived night light data. In addition, the EEA CORINE 2012 land use data is implemented with $100 \mathrm{~m}$ grid resolution to improve e.g. the biogenic emissions. Regarding aerosols, the SIze REsolved Aerosol Module (SIREAM) for aerosol dynamic and the Secondary Organic Aerosol Model (SORGAM) are applied. The CTM is driven by WRF 3.5 meteorological forecasts. In order to have reliable simulations, the one-way grid nesting method with four domains is employed, where the coarsest domain covers Europe and the finest covers Munich city area.
\end{abstract}

Keywords: Air pollution, POLYPHEMUS, Modeling, Emission, Munich

*Ehsan.khorsandi@dlr.de

\section{INTRODUCTION}

Air pollution is one of the big environmental health issues that major cities around the world are struggling with. It is, therefore, the main topic for many studies with different methods to understand the source of air pollutants and thereby developing adequate regulation methods. Air quality models are powerful tools to study air pollutants transport and chemistry with respect to the emission rates of primary pollutants and relevant weather parameters such as temperature, humidity, and solar radiation. Although the CTMs are able to handle complex physics and chemistry formulations, they are very sensitive to the quality of input data especially the anthropogenic emissions. In this study, the focus is to improve the anthropogenic emission data set for high-resolution air quality modeling over Munich city. The study is carried out in the frame of the JOSEFINA project (Joint Slovenian-Bavarian Endeavour for Improved Air Quality Analysis and Forecasting).

\section{METHODOLOGY AND DATA}

In this study, several models and data sets are used, which are introduced in the following paragraphs and the role of them in this study are described.

\subsection{Models}

The CTM used in this study is POLYPHEMUS/DLR, based on the Polyphemus model platform ${ }^{1}$ and implemented by the German Aerospace Center (DLR) for Southern Germany. The air quality model system POLYPHEMUS contains several Gaussian, Eulerian, and Lagrangian models as well as chemistry, transport, and aerosol modules. In figure 1, an overview of the DLR implementation of Polyphemus model is shown. In order to have better resolve the urban scale, an off-line nesting method is applied with four domains, where the largest domain covers Europe and the smallest highresolution $(100 \mathrm{~m})$ domain covers the Munich city area.

Remote Sensing Technologies and Applications in Urban Environments III, edited by Thilo Erbertseder, Nektarios Chrysoulakis, Ying Zhang, Proc. of SPIE Vol. 10793, 1079303 · @ 2018 SPIE

CCC code: $0277-786 \times / 18 / \$ 18 \cdot$ doi: $10.1117 / 12.2503969$ 
The Weather Research and Forecasting $\left(\mathrm{WRF}^{2}\right)$ model Version 3.5 is used for preparing weather condition and parameters as input for the Polyphemus model. The nesting approach applies 3 domains, starting with the biggest domain covering whole Europe down to the smallest one covering only Munich and Augsburg metropolitan area with $2 \mathrm{~km}$ horizontal resolution. Initial and boundary conditions for the largest domain over Europe are extracted from a 10 year MOZART $^{3}$ (Model for OZone and Related chemical Tracers) run. The highest resolution available land cover data set for Europe is EEA CORINE ${ }^{4}$ with $100 \mathrm{~m}$ resolution and 45 land type classes, with the latest release based on the year 2012. Land cover characterization is important for the model as the biogenic emissions are calculated from the vegetation type and percentage covering each grid cell. In addition, many more parameters are estimated in the model with respect to the land cover characterization including the deposition velocity and vertical diffusion. The main inputs for a CTM are anthropogenic emissions. Providing adequate emissions is a challenge as the available datasets are much coarse for urban scale applications. $\mathrm{TNO}^{5}$ emission inventory data, which is available for Europe, has $7 \mathrm{~km}$ resolution and the finest dataset for Bavaria State of Germany uses a 2 km grid (EKATBY Bavarian Emission Kataster, 2004).

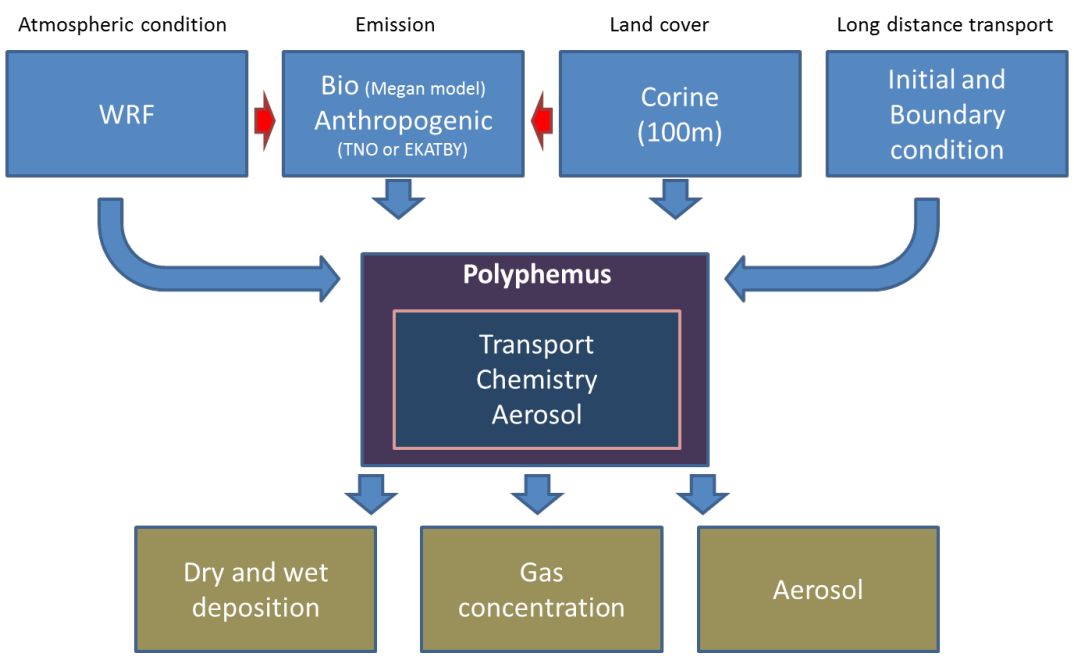

Figure 1. POLYPHEMUS/DLR model structure including data input and outputs.

In addition to POLYPHEMUS, the $\mathrm{RLINE}^{6}$ model is used to investigate the $\mathrm{NO}_{2}$ distribution on the streets level with 5 $\mathrm{m}$ resolution. The RLINE model needs a description of streets as line sources and the total amount of emissions from traffic for each street section in addition to the weather condition and street surface characteristics such as surface roughness. Figure 2 illustrates the RLINE input, output and effect of wind direction on the distribution of $\mathrm{NO}_{2}$ distribution. As it is also shown in this figure, the $\mathrm{NO}_{2}$ concentration at the defined station no. 39 near the main street depends strongly on wind direction and thus the direct comparison between observation and model result in low resolution $(2 \mathrm{~km})$ is not possible.
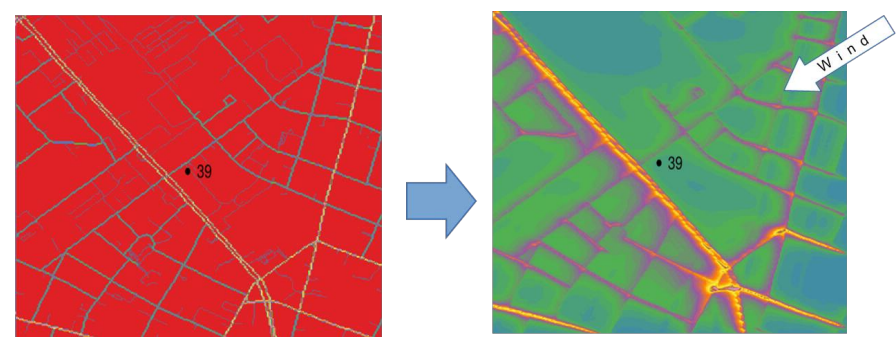

Figure 2. Street lines in $5 \mathrm{~m}$ resolution (left) and $\mathrm{R}$-line $\mathrm{NO}_{2}$ concentration results (right). The position of observation station no. 39 is indicated in the image center. 


\subsection{Anthropogenic emission map}

As the $2 \mathrm{~km}$ resolution emission map is not adequate for $100 \mathrm{~m}$ resolution air quality over Munich city, a downscaling approach is developed to prepare a $100 \mathrm{~m}$ emission map for the simulation with POLYPHEMUS/DLR model in this region. Emission datasets normally consist of estimated yearly total emissions for major pollutants in different source sectors such as transport, residence heating, and industrial sources. In order to downscale the original emission data from $2 \mathrm{~km}$ to $100 \mathrm{~m}$, the $100 \mathrm{~m}$ EEA CORINE land cover type, satellite-derived night light from the year 2015 annual composite VIIRS NOAA ${ }^{7}$ with $500 \mathrm{~m}$ resolution, and road maps from OpenStreetMap ${ }^{8,9}$ project are used, which are illustrated in Figure 3. Road shapefiles are gridded with $100 \mathrm{~m}$ resolution and weighed with respect to the road types, and the original emission for the transport sector is downscaled based on the roads' high-resolution position and type. The areal emission sources are downscaled based on night light as an activity factor for human populated areas. For the industrial sources, we apply two different methods: the first one is downscaling based on night lights, which is shown in figure 4, and the second defining industrial areas from CORINE data and relocating in these areas only and not in other parts of the city. In the second method, the industrial areas are extracted from land type data and position of point sources from TNO emission dataset. Using this information and giving the highest weight to the point sources, the industrial emission from original coarse data $(2 \mathrm{~km}$ resolution) relocated to the closest industrial area and point sources. In future, for reliability, the point source has to be corrected by exact defined values form TNO emission dataset.

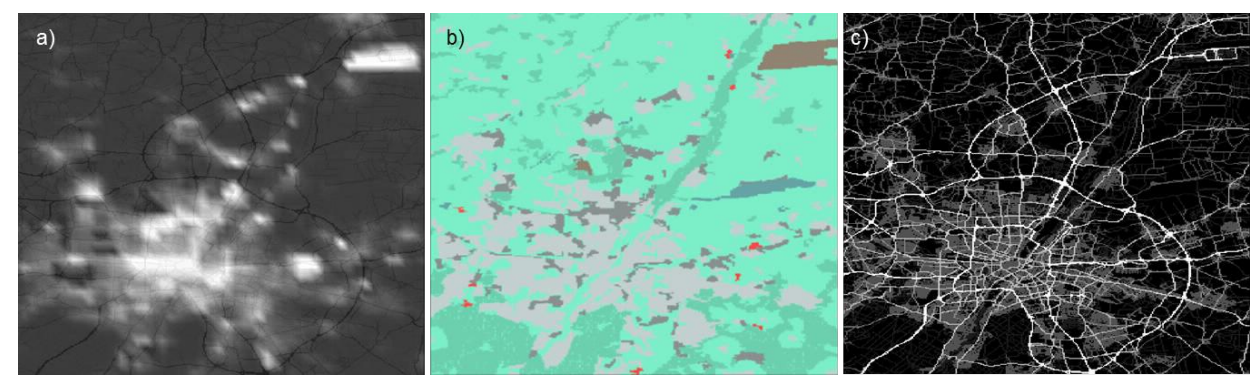

Figure 3. Munich area data for a) year 2015 annual composite VIIRS NOAA, b) EEA CORINE land cover, and c) gridded roads map from OpenStreetMap.
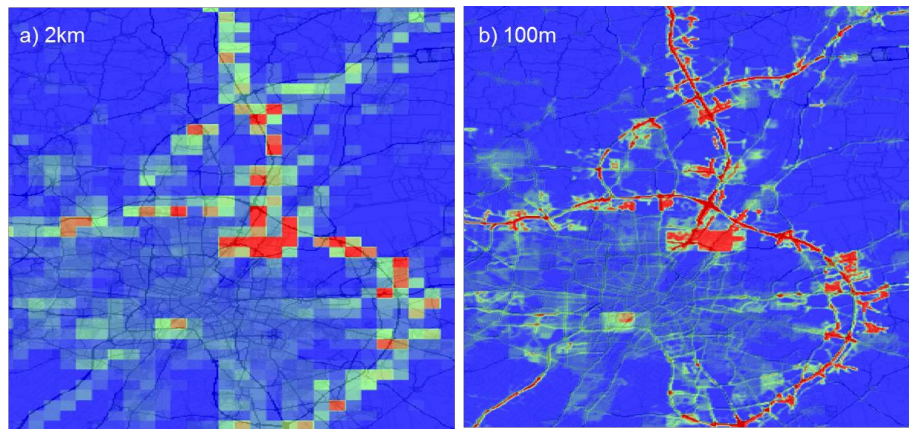

Figure 4. Emission maps from a) original $2 \mathrm{~km}$ data and b) $100 \mathrm{~m}$ downscaled emission map from all sectors.

\section{RESULTS}

As it is shown in figure 5 for the model simulation of surface $\mathrm{NO}_{2}$ concentration for second of February 2015, the downscaling method for road traffic leads to much better resolved $\mathrm{NO}_{2}$ distribution near main streets. However, downscaling of industrial emissions, based on night light results in no visible improvement, as areas with high values of $\mathrm{NO}_{2}$ (defined with red color in the plots) are following similar patterns (see especially the maximum near the domain center). In addition, the three-dimensional $\mathrm{NO}_{2}$ distribution (figure 6) highlights the importance of the vertical emission profile. For example, during the simulation the wind near surface is coming from the south pushing polluted air toward the north of the city, while the wind at around $100 \mathrm{~m}$ is coming from the west, transporting the $\mathrm{NO}_{2}$ from power plants 
and industrial areas towards the north and east of the city resulting in a well-defined NO2 plume. This indicates that misplacing the position of power plants and the vertical height of emissions might affect dramatically the result of simulations. In the shown case, the power plant emission is handled as an areal source. In contrast, figure 7 shows the clear benefit of using point source industrial emissions correction, thus the clear plume of $\mathrm{NO}_{2}$ form exact location of two powerplants and other point source are clear in this plot, and also figure 8 and 9 at different times of that day.

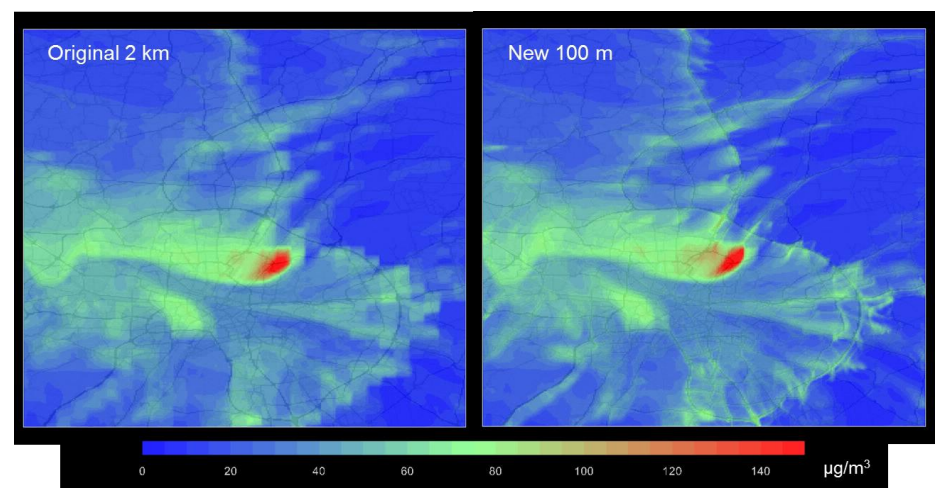

Figure 5. Model simulated $\mathrm{NO}_{2}$ concentration during afternoon of the second of February 2015, over Munich from original 2 $\mathrm{km}$ emission (left) and new downscaled $100 \mathrm{~m}$ emission maps (right).

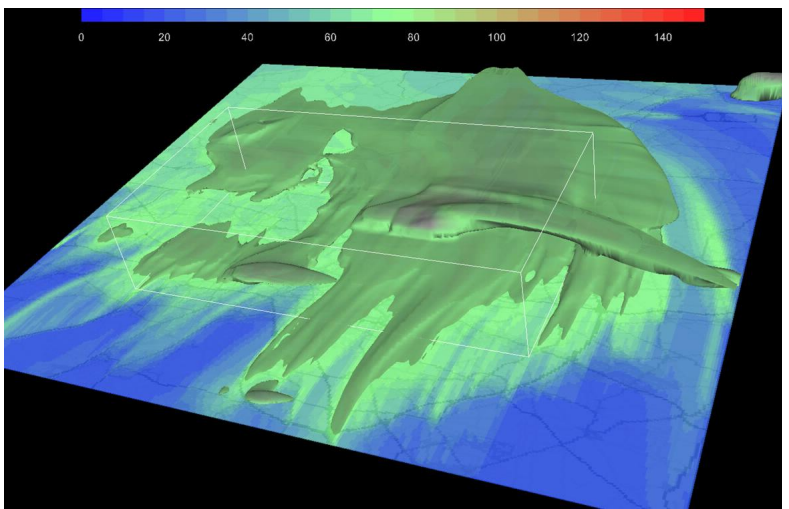

Figure 6. Simulated $\mathrm{NO}_{2}$ concentration at 8 p.m. of the second of February 2015, over Munich using new downscaled $100 \mathrm{~m}$ emission maps with 6 layers below $1 \mathrm{~km}$ height. The plume is defined by an iso-surface for $\mathrm{NO}_{2}$ concentration of $75 \mu \mathrm{g} / \mathrm{m}^{3}$. Surface concentrations are underplayed with unit of $\mu \mathrm{g} / \mathrm{m}^{3}$.

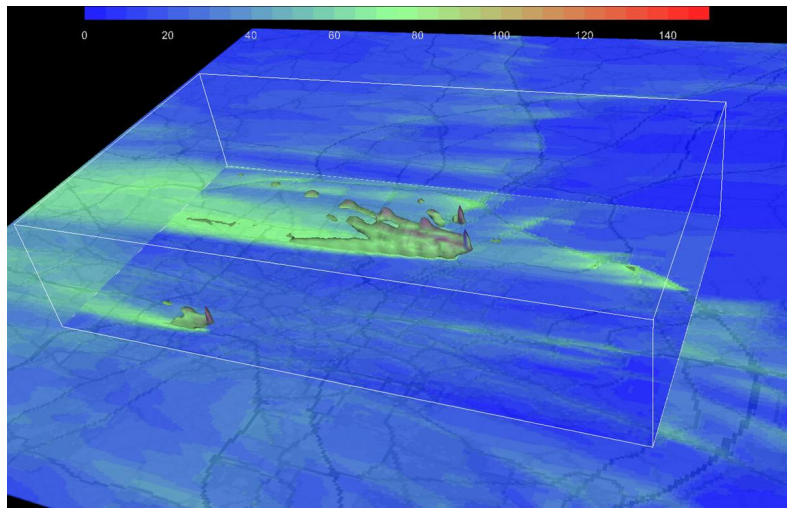

Figure 7. Same as figure 6, but for 11 a.m. of the second of February 2015, and result from correction on industrial emissions position and increasing the vertical layers below $1 \mathrm{~km}$ height up to 12 layers. 


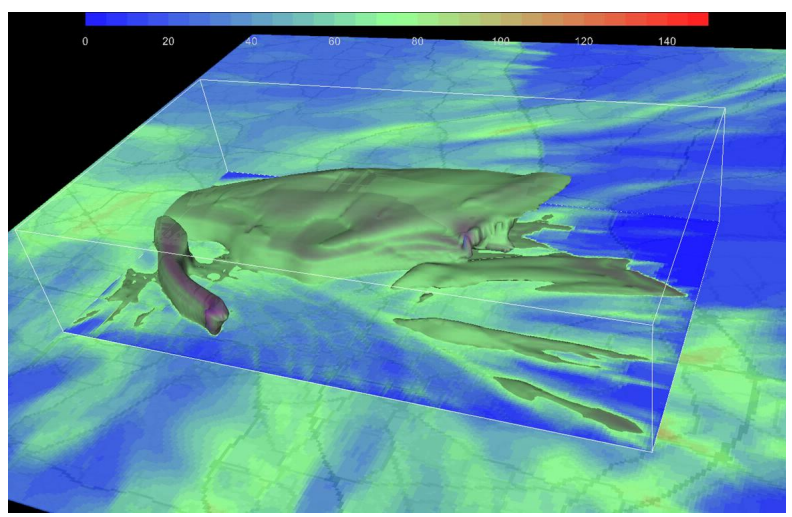

Figure 8. Same as figure 7, but for 15 p.m. of the second of February 2015.

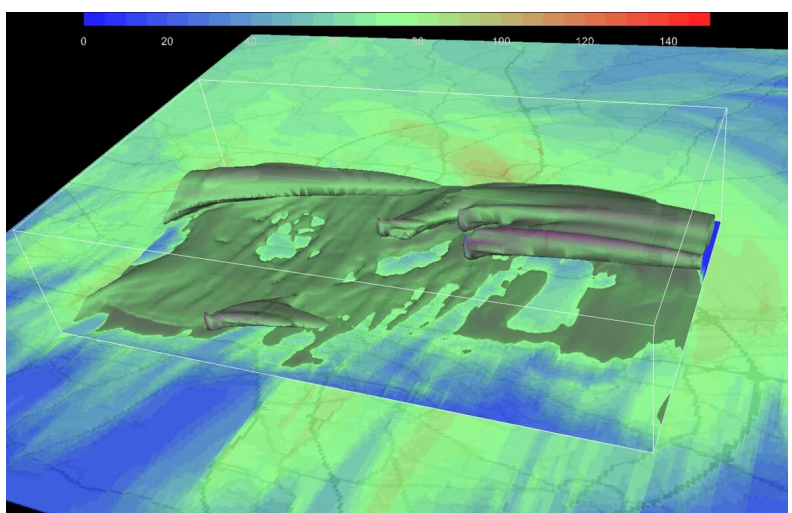

Figure 9. Same as figure 7, but for 8 p.m. of the second of February 2015.
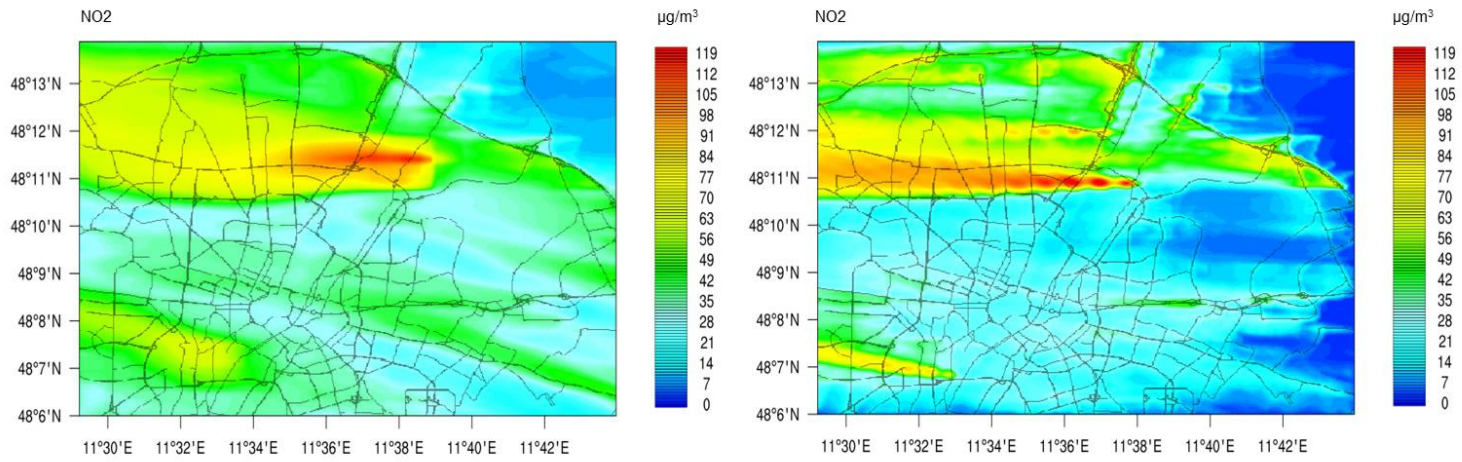

Figure 10. Model simulated $\mathrm{NO}_{2}$ concentration at 11 a.m. of the second of February 2015, over Munich from new downscaled $100 \mathrm{~m}$ emission maps (left) and with addition correction on industrial emissions position and 12 vertical layers below $1 \mathrm{~km}$ height (right).

In order to further improve the simulations, the number of model vertical layers is increased from 6 layers to 12 layers. Note that the normal observation height of monitoring stations is $2 \mathrm{~m}$, while in 6 layers configuration of the model, the first model layer height is at $20 \mathrm{~m}$. In the 12 layers configuration, the first model layer is reduced to $5 \mathrm{~m}$. The combined effect of correction with respect to point sources and increasing vertical layers is illustrated in figure 10 . The affected 
surface area by $\mathrm{NO}_{2}$ from power plants is much reduced. On average $\mathrm{NO}_{2}$ from traffic, is also reduced, while $\mathrm{NO}_{2}$ concentrations near the major traffic sources increase (Figure 10).

In order to even better resolve urban pollution in Munich, RLINE model is used to increase the resolution of simulations to $5 \mathrm{~m}$. Hence simulating $\mathrm{NO}_{2}$ concentration over Munich area using RLINE in $5 \mathrm{~m}$ resolution is difficult due to computational costs. Thus, simulations are performed in separate small subdomains. The study area and results of combined simulations for 80 subdomains are illustrated in figure 11. Note that in this case the result of RLINE was combined with POLYPHEMUS $100 \mathrm{~m}$ simulations in order to merge low-resolution background with high-resolution traffic-related pollution. Results are preliminary as the method is still under development.

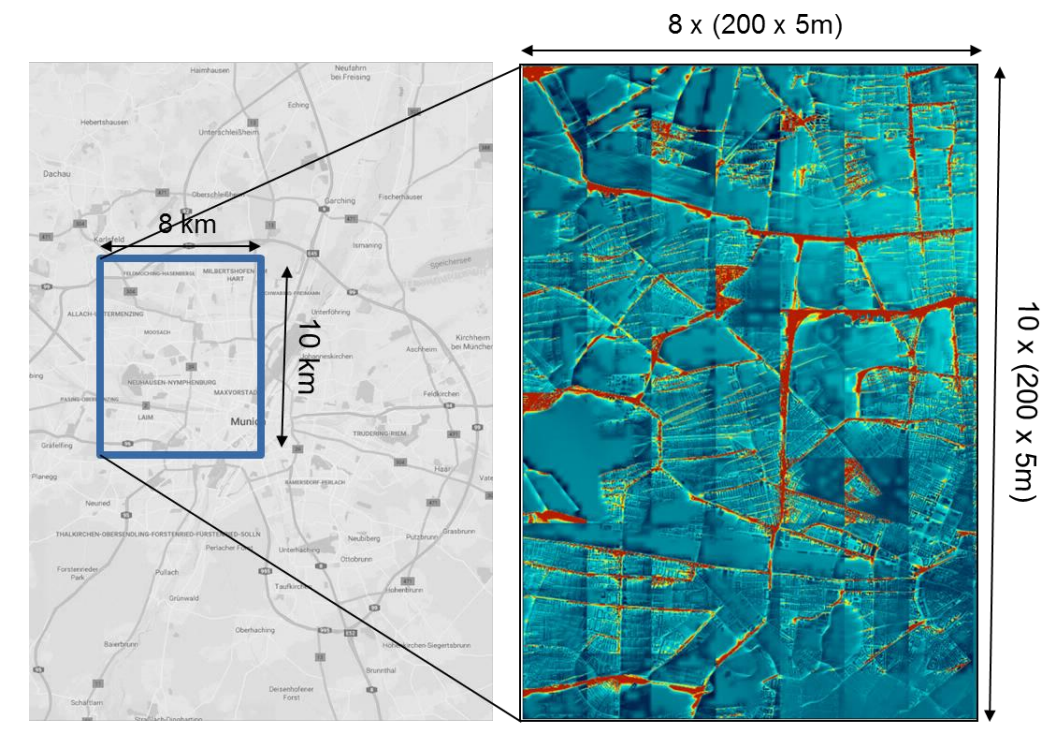

Figure 11. High resolution $(5 \mathrm{~m})$ simulated $\mathrm{NO}_{2}$ over part of Munich city from Polyphemus and R-line combined results.

\section{CONCLUSION}

In order to develop urban scale air quality modeling, a $2 \mathrm{~km}$ resolution emission inventory was downscaled to $100 \mathrm{~m}$ over Munich city area. This was accomplished by identifying populated areas using VIIRS NOAA satellite-derived night light maps and distinguishing between residence and industrial areas of the city using EEA CORINE 2012 land use classes, in addition to OpenStreetMap roads paths and types for transport source of emissions. We could show that satellite data helps to improve the emission modeling. To further increase the accuracy of the simulation, the number of vertical model layers below $1 \mathrm{~km}$ height was increased from 6 layers to 12 layers and the position of point sources were corrected horizontally and vertically. Most notably, correcting the point source has a positive influence on simulation results both close and far from the point sources. We conclude that the vertical configuration of the WRF model is crucial to capture the complex structure of urban meteorology and emissions from point sources. The different plumes reveal a strong wind shear that is not covered with vertically coarser resolutions. The next step is the rigorous validation of the model results with ambient air quality measurements and meteorological data. With respect to the satellite-based observations, data from the new missions Sentinel-5P and Sentinel-3A/B will improve modeling and evaluation of air pollutants themselves (e.g. $\mathrm{NO}_{2}, \mathrm{SO}_{2}, \mathrm{PM}$ ) even on the urban scale. 


\section{ACKNOWLEDGEMENTS}

We would like to thank the Bavarian State Ministry for the Environment and Consumer Protection for funding the

JOSEFINA project (Joint Slowenian-Bavarian Endeavour for Improved Air Quality Analysis and Forecasting).

\section{REFERENCES}

[1] Mallet, V., Quélo, D., Sportisse, B., Ahmed de Biasi, M., Debry, É., Korsakissok, I. ,Wu, L. , Roustan, Y., Sartelet, K., Tombette, M., and Foudhil, H., "Technical Note: The air quality modeling system Polyphemus", Atmos. Chem. Phys., 7 (20), 2007.

[2] Skamarock, W. C., J. B. Klemp, J. Dudhia, D. O. Gill, D. M. Barker, M. G Duda, X.-Y. Huang, W. Wang, and J. G. Powers,: A Description of the Advanced Research WRF Version 3. NCAR Tech. Note NCAR/TN-475+STR, 113 pp. doi:10.5065/D68S4MVH (2008).

[3] Emmons, L. K., Walters, S., Hess, P. G., Lamarque, J.-F., Pfister, G. G., Fillmore, D., Granier, C., Guenther, A., Kinnison, D., Laepple, T., Orlando, J., Tie, X., Tyndall, G., Wiedinmyer, C., Baughcum, S. L., and Kloster, S.: Description and evaluation of the Model for Ozone and Related chemical Tracers, version 4 (MOZART-4), Geosci. Model Dev., 3, 43-67, https://doi.org/10.5194/gmd-3-43-2010, (2010).

[4] CORINE land cover data set (https://land.copernicus.eu/pan-european/corine-land-cover)

[5] Kuenen, J. P. , Visschedijk, A.J.H., Jozwicka, M., Denier van der Gon, Hugo. (2014). TNO-MACC_II emission inventory: a multi-year (2003-2009) consistent high-resolution European emission inventory for air quality modelling. Atmospheric Chemistry and Physics Discussions. 14. 10.5194/acpd-14-5837-(2014).

[6] Snyder, M. G., Venkatram, A., Heist. D.V., Perry, S.G., Petersen. W.B., Isakova, V., (2013) "RLINE: A line source dispersion model for near-surface releases" Atmospheric Environment Volume 77, October 2013, Pages 748-756 (2013).

[7] NOAA VIIRS night light (https://www.ngdc.noaa.gov/eog/viirs/download_dnb_composites.html\#NTL_2015).

[8] Access to the road shapefile from OpenStreetMap project (http://download.geofabrik.de/osm-data-in-gis-formats-free.pdf)

[9] OpenStreetMap project official web site (www.openstreetmap.org). 